\title{
A case of rickets in a child on prolonged phenobarbitone therapy
}

\author{
B H M N Katugaha ${ }^{1}$, Indrani De Silva ${ }^{2}$, R P T Rajapaksha ${ }^{3}$
}

Sri Lanka Journal of Child Health, 2003; 32: 80

(Key words: rickets, child, phenobarbitone therapy)

\section{Introduction}

Rickets is the clinical manifestation of failure in mineralization of growing bone. Failure of mature bone to mineralize is called osteomalacia. Rickets and osteomalacia are recognized complications of long term anti-epileptic medications ${ }^{1,2,3,4}$. Anticonvulsants exert their deleterious effects on mineral and bone metabolism by inducing hepatic microsomal enzyme systems, resulting in increased catabolism and excretion of vitamin D and its biologically active products ${ }^{5}$. Though all commonly used anticonvulsants have the propensity to cause rickets, phenytoin and phenobarbitone have the greatest potential ${ }^{5,6}$.

\section{Case report}

A two years and ten month old boy had been on phenobarbitone therapy since the age of $2 \frac{1}{2}$ months, for convulsions following birth asphyxia. It was noted during clinic visits, that the child was developing bow legs and widening of wrist joints. X-rays of wrists confirmed changes of rickets (Figure 1). His alkaline phosphatase was 23 k.a.u. He was started on 1-alpha therapy and phenobarbitone was replaced with sodium valproate. His clinical symptoms of rickets improved with the above management and subsequent $\mathrm{X}$-rays showed healing ends of long bones (Figure 2). The height and weight parameters of the child fell between the 10th and 25th centiles for age. He had no clinical evidence of malnutrition. The child was adequately exposed to sunlight.

The presence of adequate exposure to sunlight makes a diagnosis of nutritional rickets unlikely but the possibility cannot be completely excluded. Epileptic children on long term anticonvulsants should be closely supervised for the development of rickets. Biochemical changes are more common than overt rickets. Since the treatment is easy and effective, the need for early diagnosis cannot be over emphasized.

${ }_{1}^{1}$ Consultant Paediatrician, ${ }^{2}$ Senior House Officer,
${ }^{3}$ Intern House Officer, Base Hospital, Matale.

(Revised version received on 3rd April 2003)

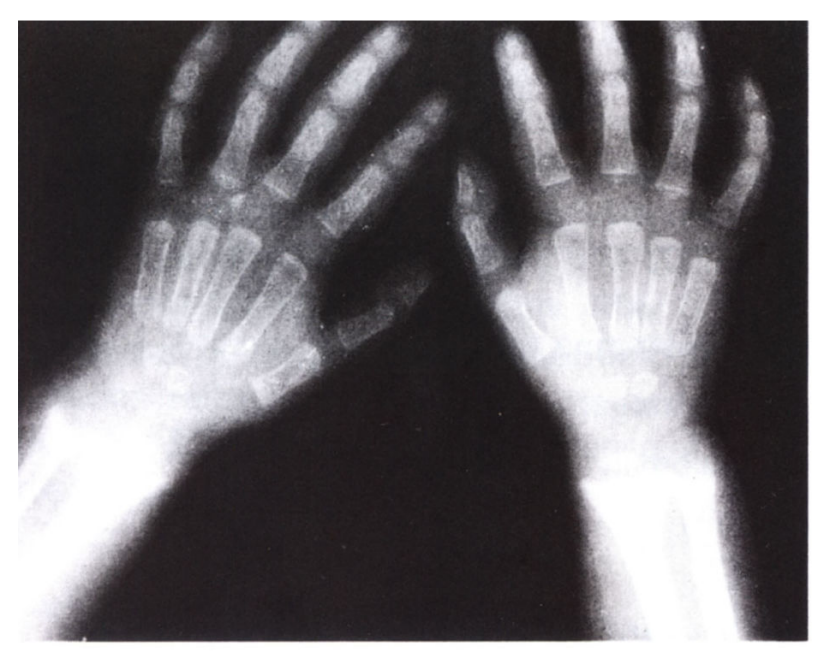

Figure 1. X-ray showing active rickets.

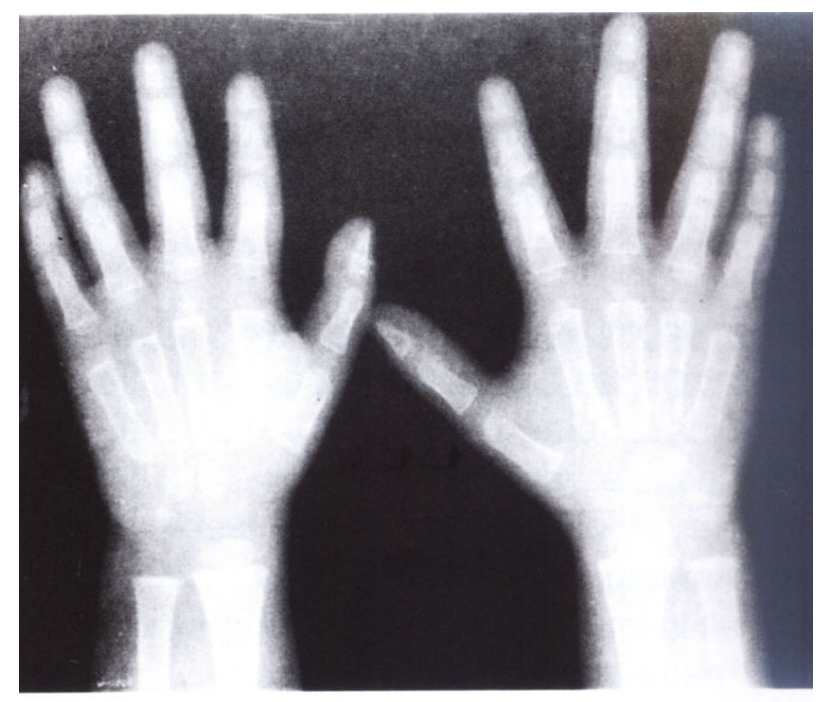

Figure 2. X-ray showing healed rickets.

\section{Acknowledgement}

We wish to thank Dr. A. Pallewatte, Consultant Radiologist, Base Hospital, Matale and Dr. Anura Rajapaksa, Central Province, Health Department for their assistance. 


\section{References}

1. Goraya J S, Gupta P N. Gupta R K, Bahadur R, Parmar V R. Anticonvulsant induced osteomalacia. Indian Pediatrics 2000; 37: 325-9.

2. Lifshitz F, MacLaren N K. Vitamin D dependent rickets in institutionalized mentally retarded children receiving long term anticonvulsant therapy: A survey of 288 patients. Journal of Pediatrics 1973; 83: 612-20.

3. Borgstedt A D, Bryson M F, Young L W, Forbes G B. Long term administration of anti epileptic drugs and the development of rickets. Journal of Pediatrics 1972; 81: 9-15.
4. Tolman K G, Jubiz W, Sannella J J, Madsen J A, Belsey R E. Osteomalacia associated with anticonvulsant drug therapy in mentally retarded children. Pediatrics 1975; 56: 45-50.

5. Hahn $\mathrm{T}$ J. Bone complications of anticonvulsants. Drugs 1976; 12: 201-11.

6. RichensA, Rowe D J F. Disturbance of calcium metabolism by anticonvulsant drugs. British Medical Journal 1970; 3:73-6. 
